Article

\title{
Things Left Unwritten: Interview Accounts versus Institutional Texts in a Case of Detention Home Violence
}

\author{
David Wästerfors \\ Department of Sociology, Lund University, 22100 Lund, Sweden; E-Mail: david.wasterfors@soc.lu.se
}

Submitted: 13 November | Accepted: 24 December | Published: 28 February 2018

\begin{abstract}
To write about clients is an established routine in countless institutional settings, regardless of the fact that clients themselves seldom feel that the produced texts mirror or summarize their experiences. But what, more specifically, is left unwritten when staff starts typing on the keyboard to insert a piece of daily life into the computer? This article draws on data on violent events in Swedish detention homes, covering, on the one hand, interview accounts collected by ethnographic researchers and, on the other hand, formal journal reports on the "same" event written by staff. The analysis of one case exemplifies what written versions of a violent ward drama omit or transform: staff members' "separation work" of the fighting actors and their local manufacturing of accountability, the involved actors' conflict explanations in terms of ethnicity, gang culture, and "the first blow", young people's way of linking their self-control to the institution's privilege system, and moral emotions as well as the significance of crucial details in the depicted course of events. The argument is not that staff should merely improve their routines of documenting events to really cover these or other facets of social life that are left behind at a detention home. Rather, the article attempts to explore why and in what sense institutional writing is incompatible with more informal, personal, and local accounting procedures.
\end{abstract}

\section{Keywords}

casebook journals; detention home; ethnography; institutional texts; interview; producing clients; total institution; written records

\section{Issue}

This article is part of the issue "'Producing People' in Documents and Meetings in Human Service Organizations", edited by Malin Åkerström (Lund University, Sweden) and Katarina Jacobsson (Lund University, Sweden).

(C) 2019 by the author; licensee Cogitatio (Lisbon, Portugal). This article is licensed under a Creative Commons Attribution 4.0 International License (CC BY).

\section{Introduction}

What happens when social life is written down? Ethnographers sometimes argue that "down" is the wrong word. Things are rather written "up" (Emerson, Fretz, \& Shaw, 1995, pp. 46-65). Whereas "writing down" portrays the writer as just detecting, "writing up" connotes creativity. No matter how careful the researchers' observations are, one can hardly argue that everything is captured, or that what is captured can be depicted accurately. Instead, ethnographers engage in an inevitably partial interpretation process, where things happening in social life are reduced and transformed. Ethnographers even inscribe (Emerson et al., 1995, p. 8); they turn their notes into exemplars of this or that tendency, setting or phenomenon, not only during the subsequent analytical work but also in the very moment of seeing, listening, and feeling. There is a compelling interpretative practice (Gubrium \& Holstein, 1997) going on when things are experienced and transcribed, involving an active subject trying to make sense of a social world by accounting for a selection of its local relevancies.

Parallel processes seem to take place in practical social work, exemplified in this article with Swedish detention homes for youth. These homes are institutions providing treatment and schooling for boys and girls, mainly with a prior criminal history or drug problems, in the form of strict control of everyday life and enforced care. The official term Särskilda ungdomshem can be translated to "special youth homes" (Gradin Franzén, 2014, p. 13) or "special residential homes for young people". 
As Enell (2017) shows, when young people end up in such homes their care begin with an assessment (in Swedish: utredning) and staff structure the assessing text in a particular way. The young people's dependency on social workers is stressed, as well as their vulnerability in general (Enell, 2017, p. 137). These written assessments typically transform young people's troubles into problems and produce clients (cf. Lipsky, 1980, p. 59). Individual biographies and idiosyncratic worries are packaged into recognizable social problems (e.g., addiction, ADHD, criminality) by words and phrases. Even though young people sometimes may evaluate the assessment themselves, and thereby personally get something out of it ("to know myself better", says Enell, 2017, p. 136), they may also get upset and protest against the conclusions in the texts (Enell, 2017, p. 132). Whereas the institutional writing seems to presume that individuals are being assessed in a context-free and neutral manner, young people take the very context of the assessment practice into account. In institutions, the youth experience "constant work" on how to behave and present themselves (Enell, 2017, p. 136). The assessment is conditioned by the fact that secure accommodation is the "assessment environment", as young people indicate (Enell, 2017, pp. 137-138). Staff observes and evaluates young people in a setting that is very similar to a total institution.

In a previous article, a colleague and I investigated wordings and rhetorical patterns in casebook journals in these institutions (Wästerfors \& Åkerström, 2015), particularly the running notes on clients in care. The institutions are obliged to write not only assessments but also these journals in order to document information about the care. The Swedish National Board of Institutional Care (n.d.) states that they function as "support for us" to provide "good and secure care". There is a need to document what has been done in the care, the authority argues, and what staff are planning to do. Decisions need background, and staff needs to communicate with each other about their work on a daily basis.

We discovered that treatment assistants writing "up" the daily life of young people in a ward were recurrently "zooming in" on the young people's behavioral problems (rather than their resources or capabilities), they took detailed notes on their mood and mood changes (but not mentioning their own or colleagues' mood), and routinely hid troubles or circumscribed staff agency and instead focused quite exclusively on how young people choose to act. Instead of writing, for instance, that a particular staff member grabbed or lifted up a client and dragged them into the isolation room, the treatment assistants used passive tense or dim expressions so that acting staff did not get into the limelight. The clients "were lifted up", "taken to the isolation room", "put down by staff", etc. - that is, the writer used words and phrases that deflected staff agency (O'Connor, 2000, p. 42; cf. Potter, 1996, p. 158; Wästerfors \& Åkerström, 2015). Thereby they indicated a uniform staff collective not really making choices or acting but simply responding- resolutely and logically - to the young people's choices and their allegedly peculiar or unusual actions. By analyzing casebook discourse, we could show that these institutions systematically depicted inmates and events in ways that reproduce internal staff loyalty and coherence.

But what we could not show was alternative and more ethnographically based images of precisely those events and associated actors that had been written up by the institution. Even though I (who had done the fieldwork) had a lot of field notes and interviews from detention homes in Sweden (Wästerfors, 2009), I had not been studying those days precisely, or events covered by the casebook notes under study. I could recognize bits and pieces and compare them with my observations and interviews, but most of the occasions in the casebook journal we studied still seemed to belong to a quite exclusive textualized world, fairly separate from what I had seen myself as a participant observer or what was uttered in my interviews. It seemed reasonable to argue that crucial aspects of actions and emotions in institutional life were left behind, but we could not specify them with regard to the described events. If, for instance, the journal depicted an event when a young boy started to argue and shout just after a telephone call with his mother, we had no other account of this event but the one written down by staff. We had notes about other everyday conflicts at the ward-including those connected to calls from the outside-but not specifically this one.

The data that this article draws on are different. Now, me and another colleague, Jesper Hambert, set out to study particular cases of a more delimited slice of social life at detention homes-violent events-and doing so with the intention to get as many versions of the "same" events as possible (as far as they had been experienced as the same by the field members). After having identified an event, for instance some guys fighting over a remote control in front of the TV at a ward (i.e., the case in this article), we tried to interview the individuals involved, the staff who came running to calm them down, the staff member who was present in the room from the beginning of the interaction, and then we also asked for the written electronic casebook notes on this very event. This made it possible to analyze not only the rhetoric of institutional texts per se but also some of the discrepancies between, on the one hand, oral and relatively spontaneous accounts of a drama in research interviews and, on the other hand, a piece of formal text about the "same" issue. Instead of comparing institutional writing with ethnographic pictures, in general, I was now able to pinpoint more exactly what staff had found relevant to "write up" in comparison to less structured, "wilder", and messier oral accounts in my data.

The "same" in "the same event" is here to be understood as an imprecise and quite practical term, as a field member's label rather than an analytical term in research. When closely analyzed, the events in the institutional texts do not seem to be the "same" as the ones orally described-they turn into something different in 
the written form, much shorter, transitory, and more institutionally correct-but still, members of the institutions count them as the "same". There is an association between the lived and the textualized dramas in this context that hardly anyone questions, even though the actors differ regarding interpretations and evaluations. For instance, with the help of just a few words from my colleague, Jesper Hambert, on the event with the remote control, along with the name of the ward and the date, it was easy for staff to identify the relevant passages in their digital texts.

We had one case, though, when staff had trouble remembering what both their record and the young inmate at issue reported, a case in which a girl was isolated after an argument outside her room at night. A staff member had written a distinctly formulated document about the decision to isolate her-we found that text during our fieldwork-and the girl could also recall and describe the event, but none of the staff that participated in taking her to the isolation cell could describe what had happened when Jesper Hambert met them some months later. One staff member started to talk about another event with another girl, but when Jesper Hambert tried to remind him of some details in the drama he gave up. He could not identify it, he could not remember. He said he was sorry and that there is "a lot going on at the ward". It is like "remembering what you did during lunch a couple of months ago".

Even if this case turned into an ethnographic failure since I could not analyze any oral account from staff (only the girl's and the written note), it was nonetheless illuminating regarding how staff generally view the very type of drama the study focused on in this setting. They all revolve around everyday events, albeit violent, in institutions where "a lot" is happening. There is, in other words, a flow of similar events going on in this field, as part of the everyday reality of treating young people with criminal experiences or other psycho-social issues in closed institutions. Some things are written up and remembered (also by staff), some are not.

\section{Data and Analysis}

Before I go into detail regarding the case at hand, I would like to briefly refer to my data and analytic method. The entire project relies on interviews and texts regarding fifteen (15) violent events. My colleague Jesper Hambert conducted fieldwork on four cases-including the case in this article-the remaining fieldwork was carried out by me, followed by the analysis and writing. Apart from this, twenty-seven (27) other young people and staff have been interviewed on the theme "how to avoid violence", which is not particularly tied to the events at issue. In total, at least seventy-one (71) individuals have been interviewed on violence and violent events in detention homes (see Wästerfors, 2018). I also have additional interviews and field notes from previous projects in the same settings (on schooling and conflict management, see Wästerfors, 2009, 2013, 2016) as background material. All interviews are ethnographically shaped (Hammersley \& Atkinson, 2007, pp. 103-120). In this article, I only make use of a tiny part of this body of data, namely those related to the event with the remote control.

I have been using a kind of double exposure when analyzing this event, or what Gubrium and Holstein (1997, p. 118) call "analytic bracketing" (cf. Ryen, 2004, pp. 31-42). On the one hand, I see field members' phrases and expressions as more or less mirroring their social reality "out there", in a naturalistic way, on the other hand, I also recognize how this reality is represented and accounted for by the very words and gestures in use. This means a constantly shifting perspective that both takes into account what people say and how they say it (cf. Wieder, 1974).

There are good reasons to believe that something happened that day in this ward-and we might call this "something" the event with the remote control-but there are also good reasons to believe that the involved actors shape and discursively "dress up" all events in various and sometimes quite diverging ways. To highlight this is the point with analytic bracketing, as Gubrium and Holstein (1997) describe it: to artfully recognize both the substantial and the constitutive character of a given piece of qualitative data. The same is true regarding the institutional writing that functions as a special point of interest and empirical contrast in this article. It is also both substantial and constitutive; it reports but it also constructs. In Gubrium and Holstein's terms, we may say that my ambition is to capture the interpretative practice of a given detention home ward and the equivalent activity-more rudimentary-in casebook journals.

\section{The Event with the Remote Control: The Formal Versions}

The event I want to elaborate upon in this article regards three boys fighting in front of the TV in a detention home in Sweden. When analyzing the staff members' and the boys' accounts in the interview data, I was able to distinguish a range of qualities that were only summarized, indicated, or completely absent in the casebook journal at issue. Since the data are rich and hard to summarize, I won't be able to go in depth regarding everything I found, but I will nonetheless exemplify most of it.

First, I would like to show the institution's textualized version of this event. This is how it was depicted in one of the journals, the one about the boy here called Casper:

Before dinner, there is a fight on the TV sofa and Casper hits and kicks another pupil, [a little later] when staff arrives and another pupil is aggressive and threatening, Casper sits completely calm in an armchair. When more staff arrive, Casper goes with them to the gaming room for a talk. In the talk, Casper states that other young people had teased and harassed him and that he had had enough and lost it, Casper also 
says that his key is missing, during the rest of the day and night he is placed in isolated care [vård $i$ enskildhet]. Casper is playing PS3 [PlayStation3] and watching movies, and staff are with him most of the time.

In the journal about Leon, it is written like this:

When Leon and other pupils are watching TV before dinner and Leon reaches for the remote control, Leon gets a blow and a kick from another pupil. Leon turns aggressive and verbally threatening. Arriving staff intervene and hold Leon back. Another pupil is also helping to calm Leon. When further staff arrive, Leon goes with them to his corridor, where he turns more aggressive and verbally threatening. Leon shoves staff a little and says that he wants more space. Staff give him this in the corridor provided that he calms down. After a talk, Leon is calmed down and willing to talk with another pupil to get an explanation. Leon is leaving his corridor after dinner and watches TV with other young people when it is highlighted that another pupil's key is missing. Leon keeps a low profile when staff are looking for the key but maintains his innocence. Leon participates when other pupils put another key [somewhere] and lets staff think that they have found the right key. Leon is searched on the first floor without remarks. Leon talks on the telephone during the night. Leon is playing table tennis during the night.

Finally, in the journal about the third boy, Ben, staff described the fight as follows:

Ben intervenes and calms down another pupil when there is a fight on the TV sofa, but when staff arrive Ben gets loud and starts to shout and scream. Ben is calmed down after a while and leaves the corridor, is informed that there will be no soccer training today and gets irritated because of this. When it becomes clear that another pupil's key is missing, Ben is the loudest one and shows distance to be guilty to having taken it [sic]. Ben is searched on the first floor without remarks, but the key at issue is found during a search of Ben's room. In a talk with the managers of the ward Ben admits that he took the key, which he found on the floor, but that he did not want to say something since he thought that staff was messing with him and he wanted to mess back.

These notes are contextualized by a range of other topics: meals, leisure activities, mood changes, cleaning, excursions, going to the gym, etc. So even though they here might seem quite long as descriptions of a fight, the notes on the event with the remote control are just glimpses in the running records as a whole.
The event as it is described in the study's interviews, on the other hand, involves more details on (1) staff doing "separation work" and immediate manufacturing of accountability, (2) staff and young people invoking ethnicity, gang culture, and "the first blow" as conflict explanations, (3) young people showing containment linked to the institution's privilege system, (4) young people's moral emotions, and (5) reflections on crucial details (the lost key, for instance) as explicitly telling and indicative in the course of events.

I will now take a detour over these aspects to show how they contribute to the case narratives found in the fieldwork. At the end of the article, I return to institutional writing and its peculiarities in this setting. Some of the twists and turns below might, at first sight, seem unnecessarily complicated, but I kindly ask the reader to carry on reading. The fact that the ethnographic stories are multilayered is a point in itself. When staff summarize this event in formal texts, most of the nuances and dynamics from the oral data are left out.

\section{4. "Separation Work" and Staff Accountability}

First, when staff hear the noise and shouting in the TV room, they come running. Several describe how they react as fast as possible, running to the room and separating the three guys, Casper, Ben, and Leon. They also start trying to figure out what is happening. Patrick, for instance, says he was sitting in a meeting on another floor when he heard the cries from below, and colleagues came running saying "more staff". He takes the stairs to the TV room, he says, and sees the guys fuming over something that he "didn't understand". He "just grabs one of them and tries to calm him down while my other colleagues grab the other one". Patrick makes up a picture for himself: it is Leon versus Casper, and Ben is associated with Leon.

Patrick and his colleagues describe it as a fight over the remote control, even though they also understand (as they say) that it must be about something else, too. Casper didn't want to give the remote control to the others, and they started fighting. They also describe how they tried to separate the individuals and started asking them questions so that they could tell "their" respective versions. Staff attempted to collect data in order to provide an explanation while they calm people down.

Jesper Hambert: What do you- what do you say to a pupil then, in that situation?

Patrick: Eh, well, what did I, you know, you- you try to sort of ask "what happened"? It's perhaps the stupid, the most stupid question you can ask, "what happened". [Laughs] But- but you'll have to do that then, and then he gets to explain his part. ${ }^{1}$

\footnotetext{
${ }^{1}$ I use some signs from a system of a simplified transcription notation in the interview excerpts in this article. A hyphen-minus (-) signifies hesitation or repetition, quotation marks signify animated or reported speech, and inside square brackets, laugh and implicated messages are pointed out. Three dots in round brackets (...) signify an excluded passage.
} 
In several interviews, it is both indicated and exemplified how staff actively collect information and synthesize it to manufacture a coherent account of the event, even though the specific contents of the account vary ("his part"). It seems to be a matter of manufacturing accountability by dyadic and interrogating talks, a sort of ethnomethod to understand and explain drama in social reality (cf. Heritage, 1984, pp. 135-178). The "separation work" and its accountability construction is somewhat indicated in the journal notes-when Casper "goes with them... for a talk", and Leon is given "more space" in the corridor and calmed down "after a talk", for instancebut it is much more visible, elaborate, and comprehensible in the interview data. When listening to the oral accounts, we may also even get a glimpse of how the event was constructed as an event. At first, Patrick "didn't understand what it was", then he started to frame it in terms of two antagonistic constellations.

\section{Ethnicity, Gang Culture, and the First Blow}

Secondly, and related to the above, staff also came up with background explanations in our interview conversations, such as ethnicity and gang culture, which are absent in the journal notes. Leon and Ben belong to the same ethnic group, speaking the same language, and Casper belongs to another (all non-Swedish). Per, the treatment assistant sitting in the very room when the fight started, points this out when he talks about how impossible it is to prevent these kinds of events. "It just said bang", he says, and he "couldn't have done anything differently". "Well yes", he adds a bit sarcastically, "if I knew all languages of the world, I could have stopped it". Per implies that Leon and Ben had said something in their shared language in front of the TV minutes before the fight, something that he and Casper had not understood. If he had understood it, Per argues, he might have prevented the fight. The background "as such" - ethnicitywas there all along, as he sees it, but it seems to have been played out and emphasized through the use of language at the brink of the fight.

In this light, the remote control turns into a superficial or even silly explanation, according to staff and Ben. "There is so much around this", Patrick says, "behind this" (Moerman, 1974).

Ethnicity is both indicated and explicitly "done" in the interview data (and exposed as a background) and a gang culture explanation follows the same logic. Per has previously worked as a security guard in urban nightlife and "lived in these gang circles", observing gang constellations. He knows, he says, "how they behave". "They do not back off (in a heated conflict situation) 'cause they don't want to leave their positions". If you back off, you will be accused of being a coward. "You fucking pussy, you just ran, ran away", Per says, indicating how gang comments might sound, as he portrays it. This explanation is particularly handy to explain the fact that Casper, Leon, and Ben remain quite close to each other in the room until staff arrive, shouting and threatening each other, throwing things, lifting up chairs, and so on. In the interviews, it becomes evident that staff observe this and present gang culture outside the institution as an explanation. Gang culture works as a narrative background to the foreground around the TV sofa, not unlike ethnicity (on background and foreground in crime descriptions, see Katz, 1988).

Leon also makes use of ethnicity as an explanation, but in combination with invoking "the first blow", which is another aspect the notes left out. To begin with, he says, in the interview with Jesper Hambert, the fight is partly his fault, too. He "could have been more careful" on the TV sofa, considering what has happened before. Ben and Casper have had fights before, he says, "they hated each other" when they stayed in another ward, and Leon himself is closer to Ben. Leon said:

And I- I- I used to mostly hang out with NNs [Leon is using the name of his and Ben's ethnic category], you know 'cause it, it feels best in that way, you know, it's nicer, and he [Casper] probably thought I was allied [with Ben] or something like that, you know, that we should beat him or something, you know. That we didn't like him, or, you know, things like that. And II always try to (...) be neutral you know, even if I hang around with him a lot, the guy [Ben], so I try to respect others' views and so, you know. Keep me in the middle so that I get out of here.

Now, Leon implies both a delicate ethnic navigation and an ethnic gaze from Casper's side. Casper associates Leon with Ben because of their shared ethnicity, so that Casper's antagonism against Leon is a matter of Leon's ethnically explained history with Ben.

Leon combines this more dynamic and relational employment of ethnicity as an explanation (now it revolves more around a social history than a category) with accounts of "the first blow". Casper was the one hitting first, Leon says. "I reached for the remote control", he says, "then he snatched the control from my hand and then he hit me and kicked me in the face.... I didn't get it at all, [it happened] without a reason". The ethnicallybased relations, though, turn into Leon's "reason" as he goes on talking, so that this typical background explanation is weaved into a situational one.

Per, a staff member, has another version: Leon shoved an elbow into Casper's chest; that was how it started. In his account, Leon delivers the first blow, but when Leon speaks the elbow disappears and Casper is the one who starts the violence. Still, by merging his account with ethnicity, Leon implies some kind of responsibility, after all. He argues that it might be understandable that Casper becomes angry since he had good reasons to believe that "we [Leon and Ben] would group up", "and beat him".

As Uhnoo (2011, chapters 5 and 6) shows, defining the first blow is utterly important in young people's stories about violence. The one who hits first is the one to 
blame the most, young people argue, even though nonphysical gestures (like demeaning comments) can sometimes be counted as a first blow. To hit back is defined as morally superior compared to hitting first. So, to narratively place the "first blow" within the actions of somebody else-the other-is a significant part of young people's moral work to account for their actions and uphold a respectful image of themselves despite using violence.

Casper's version is closer to the witness Per's, but more developed. He receives several attacks before hitting back, he claims. It is not only an elbow in his chest (as Per describes it) but also a disrespectful line: "Ey, bitch, can you change the channel?" and a slap in the face. Only after this does Casper hit back, as he tells the story. In Casper's journal, on the other hand, "Casper hits and kicks another pupil" as if there were no history at all (and in Leon's journal: "Leon gets a blow and a kick").

So the facts differ in the notes, but the very moral engagement in the detailed "first blow"-stories are also lacking. The institutional writing does not succeed in capturing the significance that the young people ascribe to concrete fight initiations and their (in this case) ethnic framing.

\section{Containment and the Privilege System}

A third and striking aspect of the event with the remote control is how the involved actors relate their way of holding back their anger with the institution's privilege system. This seems to be indicated to an extent in the casebook journal when Ben is said to lose his soccer training (even though it is not explicitly stated that this has to do with him being loud and aggressive) but it is much more evident and narratively charged in our interview data. A privilege system is Goffman's (1961/1990, p. 51) term to describe how a total institution controls its inmates by granting or denying them privileges. If you behave, you will gain benefits and relative freedom, if you do not behave, you will lose these things and your freedom is further limited.

In almost any treatment institution, certain kinds of acts are known to extend your stay (and the power of the staff) whereas other acts do the opposite. Also, detention homes in Sweden are ruled by this principle, often called token economy (for an example, see Gradin Franzén, 2014, p. 94). Young people "earn" points for good behavior and can eventually exchange these points for sought-after things. This token economy plays a peculiar role in cases of violence. To avoid being violent, or to be violent in less dramatic ways, is very much associated with "playing it cool" (another of Goffman's terms) in order to "behave". This is what Leon refers to when he talks about the advantage of keeping himself "in the middle so that I get out of here" when he describes the event with the remote control. If he goes on neatly balancing the ethnic quarrels between Ben and Casper (by staying in the middle) he does not risk being perceived as misbehaving, according to staff, and thereby he doesn't risk his chances of getting out of the institution soon. All six detention homes I have visited are, in one way or another, characterized by a privilege system, although the length of stay (formally grounded in the quite flexible law that is used to place young people in institutions to begin with) is far from the only asset at the disposal of staff. If you behave, you may get more internet time, more leisure activities or home visits, more candy or an excursion to a café or a cinema, etc. So even "small" things can be invoked to entice the inmates to act in certain ways-or withdrawn if they act badly.

"Think about yourself", "think about what you have" - phrases like that sometimes link emotional selfcontrol with the institutional system. In relation to the event with the remote control, my colleague Jesper Hambert asks Leon if he has learned to "manage anger and so", and Leon says yes. Then, Jesper Hambert asks how one learns that, and Leon says that "you only have to think about your stuff". "There is no honor or so, that's just bullshit, particularly in places like this". Rather, you'll have to be an "egoist".

You know, you should think about, if I'd do so, the consequences will be so and that's not good for me. I've come this far, 'cause I've come quite far actually. And so. And I want to get that apartment, you know. You should always think about what you risk losing, instead of just [thinking about] the moment, now.

Leon also says that he "wants to get away from here": "I think it's one of the biggest reasons why I didn't do anything against him [Casper] afterwards", he said.

So, no "honor", being an "egoist", "the consequences" - when Leon accounts for his "reasons" to hold back his violence "afterwards" (that is, directly after the fight in front of the TV, and when staff arrived to try to separate them) he draws upon the local system of privileges and makes his actions accountable in light of this. The fact that he controlled himself and abstained from fighting the staff that came running to hold him back from kicking and hitting Casper is tightly related to how "far" he has come in the local token economy.

The apartment that he wants is a so-called training apartment in a downtown area, a sort of in-betweenstation on the way to freedom, a way for those who behave to try out a normal life. Leon does not want to risk that. You only get "more and more troubles if you keep on fighting every day", he says. There are good reasons not to seek revenge. "You have to choose your battles", he says. "I was just about to get out and so, get home visits". "I didn't want to lose that".

Now, he has "dropped this", Leon says. But it could have been different. He did get very angry. He states that in similar situations:

I get so mad, you know. I get really, really, really mad, so I just wanna, I just wanna see blood. That's how mad I get. 
Leon also says that if the event had occurred in another ward, the acute ward in the (typical) beginning of the detention home journey, he would have reacted differently. Then "I would have tried to kill him", Leon says. For an outsider, all this might sound strange, but I would argue that the logic of total institutions and their privilege system provide some clarity. In an acute ward, Leon had not "gone far". At that stage, he would have nothing to loseno privilege, no promises of a training apartment, not even chances to make home visits. To restrain oneself in that situation (that stage in the token economy) would hardly be necessary, at least not to the same extent as in the ward where Leon is placed now.

In the way the casebook journal depicted the event with the remote control, there is no information regarding these issues or the actors' accounting for their actions along such lines. Similar to Enell's (2017) finding, the formal texts do not take into account what field members take into account: the fact that what is said and done in these settings belong to and depend on the very settings.

\section{Moral Emotions}

Self-controlled anger in institutional settings also has its limits. According to Jack Katz (1988, pp. 18-31), we can talk about moral emotions-strong feelings of eagerness to do the "right" thing, to put things in the moral order, to defend one's respectable identity and stand up for The Good. Katz argues that many crimes of violence are characterized by such emotions, such as humiliation turned into rage. The perpetrator strives to construct moralitya vision of something "good" - even though it certainly may not look like that from the outside, and sometimes not for the actor him or herself later on when the heat of emotions is gone.

In the event with the remote control, Leon accounts for holding back these emotions-he would be right to strike back against Casper but restrains himself in order to avoid losing institutional rewards-but Casper, on the other hand, represents something else.

Casper describes several attacks before hitting back. He is called "a bitch" and gets an elbow in his chest and a slap in his face-when he accounts for his punch and kick, he implies a feeling of "enough is enough", "now even I have to respond". He is placing the same feeling in the situation when Leon asks him why he gets mad: "I'm no doll you can hit". Casper does not explain his acts in terms of a simple and direct answer to Leon's first attack but rather as an answer after three attacks. He is emphasizing his tolerance up to that stage. But eventually also Casper wants restored respect; he doesn't want to be "a doll". Do the others think so? Now he will show them.

That is the point of Casper's story: the need to stand up for oneself. He accounts for his acts in terms of Katz' moral emotions-humiliation turning to rageand clearly communicates a feeling of retained respect. When Leon throws a glass and Casper throws the remote control, Leon says (in Casper's story) "you mother fucker", and Casper cannot stand that either. Leon has lifted up a chair, ready to throw that too, and Casper does the same. Staff stop them both.

If somebody hits you and you do not hit back, Casper says, "they'll know you're a pussy... Then they will hit you all the time":

You'll have to show them that you got, that you can, otherwise they will call you, 'cause, you know, like it is in a prison, that you're fish ["fish" was said in English], that you're fresh, you know, they can hit you anytime.

So even though all three individuals restrain themselves-Casper also gets credit from staff for having "calmed down so quickly" - there is a risk in this kind of setting to do so without limits, according to the interview data. To be a "doll" is not a preferable position, and therefore Casper needs to defend himself. He holds back but he also engages in moral emotions and associated violence, almost as if invoking a "convict code" (Wieder, 1974). First, he exercises self-control, then revenge.

Casper does not talk about upcoming home visits or a training apartment waiting for him, he does not draw on the institutional rewards to account for his actions. Rather, he draws on moral emotions. Such accounts can be seen as a more detailed and emic version of staff accounts of gang culture. With the help of actors' narratives, we may complicate the more categorical and distant explanations of staff, finding both tensions and nuances that are not really able to grasp when you come running and try to carry out treating assistant duties-tensions and nuances not included in the casebook notes.

Indeed, Casper is said to have "had enough and lost it" in the journal note, since "other young people had teased and harassed him", but the notion of standing up for oneself is much more elaborate and morally accountable in oral versions.

\section{Crucial Details}

Finally, a fifth aspect: crucial details. Per, for instance, talks about several details in the course of events that seem hard to ignore once you know them. Just before the incident, Ben walks to the toilet but forgets his key to his room on the sofa. Per observes this as well as the fact that Leon takes the key and offers it to Casper, but Casper says he doesn't want it. Per interprets this as a prequel to the violence-a way for Leon to plant a reason for him and Ben to strike against Casper. If Casper would have taken the key it would be easy for Leon to "disclose" this when Ben returned from the toilet, so that they both could be righteously angry with Casper. They could have started a fight with him with a key theft as a cause. "Leon and Ben could have attacked the third guy for a reason", Per says.

Now, this reason didn't crystallize, but the very attempt from Leon's side functions as an indication in ret- 
rospect, according to Per's story, a sort of warning that intrigues were in the making. It is also a nice illustration of the social need for reasons to start a fight. In line with Uhnoo's (2011) and Jackson-Jacobs' (2013) findings, hitting back is morally superior and practically easier compared to hitting first.

In Ben's story, there are other details. In his interview he talks about Casper being a liar and that he cannot be trusted, he even tested him once at another ward to prove this. Ben came up with a story of having a hidden knife in his room and told this to Casper, and later the same evening staff decided to arrange an extra search in the rooms. No knife was found, of course, since Ben has made it all up, but Ben took it as evidence for Casper being a collaborator with staff. "I started to suspect something, that he was the one who had told [staff] something". That is one of the reasons he cannot be trusted and therefore actually deserves to be corrected and excluded. When the fight broke out in front of the TV, Ben immediately stood up on Leon's side. He tried to calm him a bit, but eventually, he turned very angry with Casper, shouting "mother fucker" to him and throwing a chair towards him-all according to his own description. Afterwards, staff praises him for trying to calm Leon but criticize him for throwing the chair. He loses an outdoor activity because of that (probably the soccer training, mentioned in the journal notes).

Casper mentions yet another detail. After the fight, it turns out that his room key was lost. It was lying on the sofa in front of the TV, attached to a chain that Casper has had "since he was a kid", as he says. The rooms were searched later on and the key was found but not the chain-this is also mentioned quite extensively in the journal notes. Somehow Leon and Ben had managed to take and hide Casper's key during the fight, and then probably threw away the chain that Casper was apparently very fond of. It's hard to not look upon this story as revolving around revenge-Casper portrays Leon and Ben as striking back against him with theft. "Then they had taken it from me", Casper says. "You know, they have bullied me so fucking much the whole time".

The keys, the chain, the story about the knife at another ward-the narrators of this event consecutively employ details to unfold its drama and account for its hidden dimensions. Details are treated as telling, revealingthrough them the narrators may weave their morals and set the evaluations right. Parts of the stories regarding the keys are included in the journal notes but in these texts they are not treated as indicative in the same sense as in the interviews. For Per, the prequel with the key proves that Ben and Leon were, in a sense, waiting to strike against Casper and that this constellation was fixed. For Casper, the epilogue with his key and chain symbolizes his ongoing victimization. For Ben, the fictive knife theft at another ward proved that Casper was no one to trust.

In the journal notes, on the other hand, the words about the key are not explicitly interpreted but rather treated as a list of facts ("the key at issue is found during a search of Ben's room"; "Ben admits that he took the key"; "[Leon] lets staff think that they have found the right key") even if they seem implicitly dressed up as moral facts. The institutional writing does not capture the actors' way of using the details representatively and as a resource for conflict accounts.

\section{Institutional Omissions and Transformations}

Similar to other events in my study, the event with the remote control shows how multifaceted social life at a detention home can be, perhaps especially so when it comes to violence. Analytically we can switch between, on the one hand, "diving" into the situation and naturalistically reconstructing a course of events as careful and nuanced as possible and, on the other hand, identifying how various actors present it and perform their roles, moral points, and positions. Gubrium and Holstein's (1997, p. 118) analytic bracketing is helpful: a continuous and dialectal procedure to acknowledge both local substances and local constitutive activities. It is a matter of accepting and balancing the tension between "whats" and "hows".

The staff come running to the TV room, separating the fighting individuals and start manufacturing accountability. They put together bits and pieces-observational, moral, dramaturgical, etc. - to get a rough image of what has happened. One staff (Per), who was there "from the start" (in the room) not only suggests category-based explanations but also adds his more detailed view: a prequel with a key, and another "first blow" that others took for granted, and explicit interpretations based on the details. Ethnicity and gang culture are suggested as background explanations, but they are also weaved into the foreground in the actors' narratives. Staff and youth argue that they can see the consequences and employment of both.

The young people also deconstruct the first blow and discern finer variants. Even the ones feeling targeted by violence (Ben, for instance) express some understanding of it, and they all emphasize that it could have been much worse. Step by step, the accounts in the interviews start dealing with self-control and how it is embedded into the institutional privilege system. The ward gives benefits to you if you behave but it withdraws them if you misbehave. To withhold acting out one's moral emotionsstrong feelings of doing Good, in Katz' (1988) terms-and to think only about "yourself" and your future are identical to following the institution's incitements. But the event with the remote control also shows that such selfcontrol must be balanced with demonstrations of selfassertion, as the young people see it. Violence can be performed to avoid being bullied (cf. Athens, 1992, 1997), even if institutional privileges are put at risk.

In the casebook journal, we get much more truncated versions. In a way, they resemble the sketch given by the staff who came running to the room and who was re- 
ferring, at least to begin with, to their first impressions. "Before dinner, there is a fight on the TV sofa", it says in the journal about Casper. He "hits and kicks" another young man. Casper is said to have argued that "other young people had teased him and harassed him", "he had enough and lost it" (in Swedish: tappade det), meaning he lost his temper and self-control. There are some outlines of backgrounds, as in Casper's journal where it is said that he has been teased and harassed by others before, and there are similar outlines of significant details, as in Leon's and Ben's journals where the missing key is accounted for. But the picture is still much more compressed.

There is nothing on the moral analysis and debate in the texts - nothing about the notion of the first blow and its low moral value among young people in general, almost nothing about the more durable and tense background relation between Casper, Leon, and Ben. There are no fully understandable prequels regarding the room key, and nothing on the limits of containment and its embeddedness in a privilege system, as the field members themselves see it. In the journal about Leon, it says, very briefly, that he gets "a blow and a kick by another pupil" when he reaches for a remote control. In the journal about Ben, it says that "there is a fight on the TV sofa" this day. When staff arrives, Ben "gets loud and starts to shout and scream" but he calms down after a while. Casper's key is found in Ben's room-no, "another pupil's key" is found there, it says in the institutional text about Ben.

The latter formulation points to a striking and crucial fact when it comes to textualized events in these kinds of institutions. Casebook journals are characterized by strict individualization. In Ben's "journal world" there is no Casper or Leon, just "another pupil", "another boy", or the like-and vice versa when it comes to Casper's and Leon's journals. Staff writing about a given inmate is about that single inmate, not about his or her relations to others, at least not in terms of concretely described personal relations. When "another pupil" or the like is mentioned, it is never pointed out that this is the same "other pupil" as, for instance, the one in yesterday's note. We need sources outside journals to obtain descriptions of concrete courses of events or chains of interactions in which other young people-and staff-are crystallized, and in which the individual as a person gets shape and contour, as well.

Staff writing does not engage in substantiating, understanding, or unfolding relations. Rather, actions are presented in ways that render them quite atomic. When relations are depicted, they are articulated in terms of what they result in for the individual at issue: others had "teased him and harassed him [Casper]".

The point with zooming in a transient situation like the event with the remote control with the help of ethno- graphic interviews beyond the institutional writing is not only to get a glimpse of how violence is constituted if studied in detail-by a series of words, gestures, attacks, attributed motives, diverging and converging accounts, etc. The point is also to clarify what the institutional writing omits or transforms. When reporting the event with the remote control, there are no words typed into the digital journal system on the implications of the institution, its social life, its rules and individual staff actors. There are only observations of troublesome clients and their moral characters.

In fact, by only drawing on casebook journals, it might be difficult to trace how Leon, Ben and Casper's fight are one and the same. The date, the TV sofa, the stories around the key and the remote control can function as clues, but in other respects, the notes are written as to reflect and report on an individual's actions and his conditions. They are not written to mirror social life at the ward, let alone emerging situations of violence within this social life. Many qualities tied to sociality are absent or merely vaguely indicated, but they are widely and vividly employed when the event is recounted and dramatized in oral storytelling to a visiting researcher.

\section{Conclusion}

Casebook journals are made up of running notes on care and surveillance that form material for upcoming placements and treatment programs. As Enell (2017, p. 137) shows regarding the written assessments in this setting, these texts may have varying significance in practice. The consequences depend on how caseworkers act upon the texts, how they are employed to legitimize this or that route in the social service system. Caseworkers make use of the texts to account for their decisions, so in that sense their reading turns crucial for young people, but hardly the texts as such. Rather, the significance is a matter of texts-plus-professional-interpretation. "The written assessment in itself had less or no meaning to the young people" (Enell, 2017, p. 137).

But for the sake of social science, contrasts between oral and formally written versions of institutional life can be quite illustrative. What is put into the record (the texts as such) and what is left out says something about how client-producing institutions function and define themselves.

If, again, compared with researchers' production of ethnographic field notes (Emerson et al., 1995, pp. 8-12), it is clear that one cannot separate the writer's methods from findings in the institutional text production. "What the ethnographer finds out is inherently connected to how she finds it" (Emerson et al., 1995, pp. 8-12). The writing method-to employ an individualizing gaze, depicting Leon, Ben and Casper (and all other young peo-

\footnotetext{
${ }^{2}$ By this comparison, I do not mean to stress similarities between ethnographers and staff at a detention home. Ethnographers are trained in observation, note taking, and analysis whereas detention home staff are not. Rather, I want to point out that there are some insights in the method literature regarding procedures in which ethnographic observations are turned into texts that are probably relevant also for other observations turned into texts, such as in social work.
} 
ple in care) as troublesome clients who once in a while get very agitated and involved in heated fights-will inevitably produce the "finding" that Leon, Ben and Casper are especially distressed individuals, acting in especially unpredictable or problematic ways, although quite independent of the fact we see clearly in interviews: that they are placed together in a TV room and put under the pressure to get along in a total institution. A casebook journal is stylistically and rhetorically organized in a way that not only facilitates this production of "findings", it also rules out or obscures alternative methods and their potential results.

In the notes about Leon, for instance, staff cannot start writing in terms of "and then Leon talked again about his long and antagonistic relation to Casper, and Casper talked about being bullied by Leon and Ben", since (1) staff are supposed to anonymize others, (2) staff are supposed to treat such facets as too remote from "the case", and (3) the case is client Leon, not the fight. The interpretative practice of an institution does not define such accounts as something to "write up". The writing is supposed to be focused on this or that youth in treatment, not on sociality in a ward and certainly not on situationally embedded logic of a total institution.

Ironically, though, my data show that staff do observe and articulate what is left out in the formal notes, so the reason behind this division cannot be understood in terms of a lack of staff or youth capacity. The folk sociological gaze is there-among staff, among youth-but it is not supposed to be inscribed into the texts. The involved actors narrate alternative variants of conflict accountability, and they do so not only in medical or category-based terms but also in interactionist and institutional ones. But interactions or institutions are not the targets for therapy and incarceration. The young people are the targets and the associated texts work as icons for that practice. This means that the function of writing an institutional text is less about representing clients and more about reproducing a particular kind of institution and its raison d'être. Institutional writing is part of the "endogenous reproductive processes through which institutional realities are maintained" and as such, it is largely invisible for field members (Heritage, 1984, p. 232). Staff may think that they write about (for instance) Leon but-sociologically-they write for the institution. The first is evident and talked about, whereas the latter is not really noticed.

Could more nuanced written descriptions improve the understanding of social life in a total institution and troubled young people's lives? Yes and no. Treatment assistants would probably benefit from a freer genre to write within. Patterns of interactions could be discovered, typifications deconstructed and the institution (and not only the individual) could be discovered analytically-by staff and youth. Some "regrouping of particulars", as Heritage (1984, p. 230) puts it, is basically possible, even a shift of paradigms if, for instance, the staff were more educated in ethnography and social theory. But no matter the style and wording, no writer can capture social life in full. Accounting procedures, ethnomethodologists teach us, are infinite. There is no final word on social reality, no way of settling a perfect or complete account. "Any description is thus inherently selective in relation to the state of affairs it describes" (Heritage, 1984, p. 150).

By juxtaposing institutional texts with interview accounts from ethnographic studies, we can learn what this means in social work practice. To expand and complicate institutional texts for its own sake, to "cover" more and more of the drama in the wards, is essentially a futile project. Given the fact that young people in these settings do not want more texts, it is also ethically dubious. What these young people want is to get out of the institutions and get on with their lives - to feel better, to improve their social relations, and to attain more appreciated social identities through studies and work. In order to reach this, they prefer personal interactions (Levin, 2017, pp. 40-43) and not texts, no matter how precise.

\section{Acknowledgments}

I am very grateful for precise comments and helpful criticism from four anonymous reviewers and the editors. I also want to thank Jesper Hambert who helped me a lot with data collection.

\section{Conflict of Interests}

The author declares no conflict of interests.

\section{References}

Athens, L. (1992). The creation of dangerous violent criminals. Urbana, IL: University of Illinois Press.

Athens, L. (1997). Violent criminal acts and actors revisited. Urbana, IL: University of Illinois Press.

Emerson, R. M., Fretz, R. I., \& Shaw, L. L. (1995). Writing ethnographic fieldnotes. Chicago, IL: Chicago University Press.

Enell, S. (2017). 'I got to know myself better, my failings and faults': Young people's understanding of being assessed in secure accommodation. Young, 25(2), 124-140.

Goffman, E. (1990). Asylums. Essays on the social situation of mental patients and other inmates. New York, NY: Anchor Books. (Original work published 1961)

Gradin Franzén, A. (2014). Disciplining freedom. Treatment dilemmas and subjectivity at a detention home for young men. Linköping: Linköping University.

Gubrium, J. F., \& Holstein, J. A. (1997). The new language of qualitative method. Oxford: Oxford University Press.

Hammersley, M., \& Atkinson, P. (2007). Ethnography. Principles in practice. London: Routledge.

Heritage, J. (1984). Garfinkel and ethnomethodology. Cambridge: Polity Press. 
Jackson-Jacobs, C. (2013). Constructing physical fights: An interactionist analysis of violence among affluent, suburban youth. Qualitative Sociology, 36(1), 23-52.

Katz, J. (1988). Seductions of crime. Moral and sensual attractions in doing evil. New York, NY: Basic Books.

Levin, C. (2017). Det sociala ansvarets organisering. Social barnavård mellan byråkrati och solidaritet [The organisation of social responsibility. Social child care between bureaucracy and solidarity]. Lund: Studentlitteratur.

Lipsky, M. (1980). Street-level bureaucracy: Dilemmas of the individual in public services. New York, NY: Russell Sage Foundation.

Moerman, M. (1974). Accomplishing ethnicity. In R. Turner (Ed.), Ethnomethodology (pp. 54-68). Harmondsworth: Penguin Education Series.

O'Connor, P. (2000). Speaking of crime: Narratives of prisoners. Lincoln, NE: University of Nebraska Press.

Potter, J. (1996). Representing reality. Discourse, rhetoric and social construction. Thousand Oaks, CA: SAGE.

Ryen, A. (2004). Kvalitativ intervju. Från vetenskapsteori till fältstudier [Qualitative Interviews. From theory of science to field studies]. Malmö: Liber.

Swedish National Board of Institutional Care. (n.d.). About the Swedish national board of institutional care. Statens institutionsstyrelse. Retrieved from www.stat-inst.se/om-sis/om-webbplatsen/other-lan guages/the-swedish-national-board-of-institutionalcare

Uhnoo, S. (2011). Våldets regler. Ungdomars tal om våld och bråk [The rules of violence. Young people's talk about violence and disputes]. Göteborg: Daidalos.

Wästerfors, D. (2018). Vanskligt och kort. Om våldshändelser bland unga på institution [Risky and short. On violent events in Swedish detention homes]. Manuscript submitted for publication.

Wästerfors, D. (2009). Konflikthantering i ungdomsvård ur ett sociologiskt perspektiv [Conflict management in youth care from a sociological perspective]. Stockholm: Statens institutionsstyrelse.

Wästerfors, D. (2013). Lektioner i motvind. Om skola för unga på institution [An uphill struggle. On school work for young people in institutions]. Malmö: Égalité.

Wästerfors, D. (2016). Playfights as trouble and respite. Journal of Contemporary Ethnography, 45(2), 168-197.

Wästerfors, D., \& Åkerström, M. (2015). Case history discourse: Rhetoric of troublesome youngsters and faceless treatment. European Journal of Social Work, 19(6), 871-886.

Wieder, L. D. (1974). Language and social reality. Lanham, MD: University Press of America.

\section{About the Author}

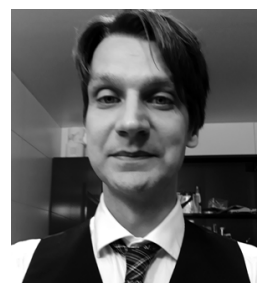

David Wästerfors is Associate Professor in Sociology at the Department of Sociology, Lund University, Sweden, and teaches in sociology and criminology. His research is often focused on interactions, institutions, emotions and social control. He has completed three research projects with ethnographic data from Swedish detention homes (on conflicts, schooling and violence). A related interest is qualitative methodology, shown in his latest book Analyze! Crafting Your Data in Qualitative Research, written with Jens Rennstam and published in 2018. 